MT，DMT がすぐれていると考えられる.

(昭和 34 年 9 月, 本会第 8 年会にて一部発表)

$$
\text { 交献 }
$$

1) 柳原 正, 俣野宜久, 川瀬 晃：本誌，7，496， 500 (1958) ; 8, 10, 14 (1959) ; 9, $344(1960)$. 川瀬 晃：同上, 11, 621 (1962).

2) 中川元吉, 和田弘子：日化，83，1185 (1962).

3) 川瀬 晃：本誌， 11，628 (1962).

4) 川瀬 晃: 未発表.

5) E. B. Sandell : "Colorimetric Determination of Traces of Metals", 3rd Ed., p. 80(1959), (Interscience Pub., New York). is

Determination of nickel with o-(2-thiazolylazo) phenol derivatives. Akira Kawase (National Research Institute for Metals, Meguro-ku, Tokyo) The reaction of $o$-(2-thiazolylazo) phenol com- pounds ${ }^{1)}$ and nickel gives products with red-purple or blue coloration, and the chelates can be extracted with chloroform. Their molecular extinction coefficient at their maximum absorption wavelengths around $600 \sim 700 \mathrm{~m} \mu$ are $3 \sim 5 \times 10^{4}$ (Table VI) and they can be applied for determination of trace nickel.

The combining ratio of the metal to the reagent was $1: 2$ (Fig. 9 and 10), and the presence of $1: 1$ chelate in an aqueous medium at low $\mathrm{pH}$ (Fig. 10 and 11) was also recognized.

The conditions for determination of nickel by these reagents were established (Table IV). NT and $\mathrm{HMT}^{3}$ ) were suitable for the photometric determination, and SNT, RT, MT, and $\mathrm{DMT}^{3}$ ) were superior as metal indicators. p. 80 (1959), (Iaterscience).
(Received May 6, 1963)

\title{
o-(2-チアゾリルアゾ)フェノール誘導体によるコバルト(II) の定量*
}

\author{
川瀬晃**
}

標記化合物はコバルトと鋭敏に反応して赤紫または青色を呈する。このキレート化合物はクロロホル 么によく抽出される．極大波長でのモル吸光係数は $2 \sim 5 \times 10^{4}$ 程度で感度のよい試薬である.

抽出されたキレート化合物は金属と詿薬が 1:2の比で結合している.抽出法を用いれば微量のコバ ルトを感度よく定量することができる。これら化合物のうちでは NT，HMT が抽出試薬としてすぐれ て扰り，金属指示薬としては SNT, MT, DMT, RT などがよい.

\section{1 緒言}

o-(2-チアゾリルアゾ) フェノール化合物は1; 3) コバ ルト(II) と鋭敏に反応し, 赤紫または青色の呈色を示 す. この反応を用いて微量の金属のオンの定量を試み た. 銅さおよびニッケル3)の定量についてはすでに報告 したが，その検討の結果，適当と思われる試薬 10 種を 選んでコバルト(II)の定量を試みた。

\section{2 試薬および装置}

標準コバルト溶液 : 高純度コバルト粉末 $0.5893 \mathrm{~g}$ を 硝酸に溶解し $1 l$ とする.この溶液を適当に水でうすめ て使用する. その他の詓薬, 機器は前報3)と同じであ 万。

*o-(2-チアゾリルアゾ)フェノール誘導体の分析化学 的研究（第 4 報）

** 科学技術庁金属材料技術研究所 : 東京都目黒区中目 黒 2 丁目
3 溶媒の選択

o-(2-チアゾリルアゾ) フェノール 化合物はコバルト （II）と反応し, 赤紫色または青色に变化するが, このキ レートは水に難溶性で, 濃度が高いときには沈殿とな る.

キレート化合物を抽出, 吸光光度法でコバルト(II)を 定量するために適当な溶媒を選んだ.

クロロホルム, イソアミルアルコール, MIBK にはよ く抽出される.ベンゼン, 四塩化炭素による抽出は前三 者によるほどよくはない, MIBK は条件によってはェ マルジョンになりやすく, 分相性がわるい，イソアミル アルコールは水との相互溶解度が大きく, 臭気もつよい のであまり適当でない。

クロロホルムは分相性もよく, 水との相互溶解度も少 なく,よい抽出溶媒である. ただし SNT, RT はク口 ロホルムに抽出されないので水溶液中で定量することに 
した。

4 コバルト (II) キレートの吸収曲線

\section{$4 \cdot 1$ コパルト過利のときの吸収曲線}

コバルトが試薬に対して大過剩に存在するとき生成す るキレート化合物の吸収曲線を測定した。

適当な $\mathrm{pH}$ の緩衝溶液 $10 \mathrm{ml}$ に $10^{-2} M$ コバルト溶液 $1 \mathrm{~m} l$ および試薬溶液 $1 \mathrm{~m} l$ を加えてクロロホルムで抽 出し, 抽出相はクロロホルムで正確に $25 \mathrm{~m} l$ にうすめ, クロロホルムを対照液として 350～750 $\mathrm{m} \mu$ の吸収曲線 を測定した， RT， SNT は同様の組成の水溶液を水を 対照液として吸収曲線を測定した. 測定結果は Fig. 1, 2, Table I に示した.

Table I 吸収曲線

\begin{tabular}{lccc}
\hline \hline 試 薬 & \multicolumn{2}{c}{ 極大吸収 $(\mathrm{m} \mu)$} & $\mathrm{pH}$ \\
\hline NT & 555 & 417 & 7.49 \\
MNT & 557 & 418 & 7.49 \\
HNT & 566 & 416 & 8.50 \\
PNT & 559 & 434 & 8.50 \\
MT & 612 & 398 & 7.49 \\
HMT & 624 & 411 & 7.49 \\
HCT & 601 & 413 & 8.01 \\
DMT & 591 & 410 & 8.01 \\
RT & 509 & & 5.98 \\
SNT & 542 & 394 & 5.98 \\
\hline
\end{tabular}

$\mathrm{RT}$ を除く他の吸収曲線は $420 \mathrm{~m} \mu$ および $\mathrm{NT}$ 系で は $560 \mathrm{~m} \mu$ 付近, その他では $620 \mathrm{~m} \mu$ 付近に単調な極大 を有し，ニッケルキレートの場合とは異なり微細な吸収 はなく，銅キレートと似ている。

$\mathrm{SNT}$ は $\mathrm{pH} 5$ では $538 \mathrm{~m} \mu$ に極大吸収がある。 $\mathrm{pH}$ 6 以上では $542 \mathrm{~m} \mu$ に吸収が移動する。

\section{$4 \cdot 2$ 試薬過剩の場合の吸収曲線}

試薬が過剩に存在しているとき生成しているキレート の吸収曲線を求め, コバルト過剩の場合のキレートの吸 収曲線と比較した．試薬の吸収が大きいので正確な吸収 曲線の測定は困難であるが，ニッケルキレート3）場合 と同様に一定の組成のキレートが生成しているとし，残 存する試薬の量を計算し, その濃度の対照液を用いて吸 収曲線を測定した。

試薬溶液 $1 \mathrm{~m} l に \mathrm{pH} 8.0$ の緩衝液 $10 \mathrm{~m} l$ を加え, $10^{-4} M$ コバルト溶液 $1 \mathrm{~m} l$ を加え, $10 \mathrm{ml}$ のクロロホル ムで抽出する.抽出液は $1: 2$ のキレートが生成してい ると仮定し, $0.8 \mathrm{~m} l$ の試薬溶液を緩衝溶液 $10 \mathrm{~m} l$ に加 えて抽出した溶液を対照液として $350 〜 750 \mathrm{~m} \mu$ の間の

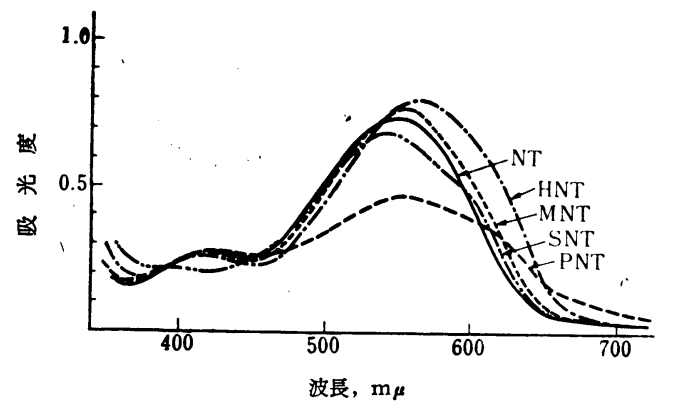

Fig. 1 コバルトキレートの财収曲線（コパルト過 剩)

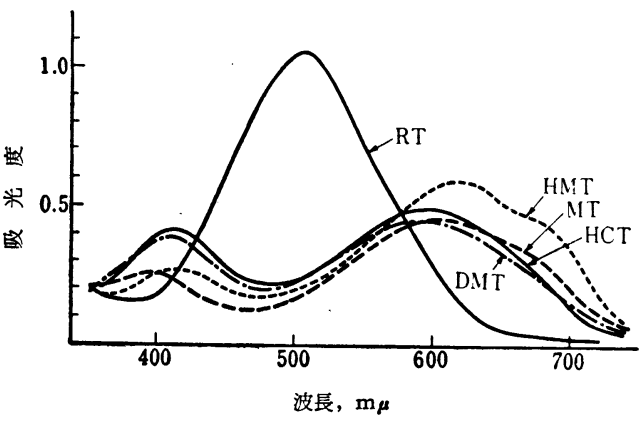

Fig. 2 コバルトキレートの忣収曲線（コバルト過 剩)

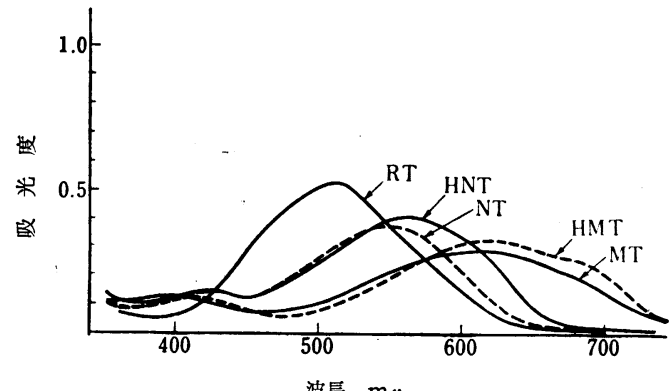

Fig. 3 コバルトキレートの财収曲線（試薬過剩）

吸収曲線を測定した。ただし，RT，SNT は緩衝溶液 (pH 6.0) $5 \mathrm{ml}$ を用い, 他注同量の溶液を用い, 水溶液 として測定した.この結果の一部を Fig. 3 に示した.

SNT を除いては，いずれもコバルト過剩の場合に生 成し，抽出されたキレートと同一であり，吸収の大きさか ら $1: 2$ のキレートが生成していること示している.

1:1 のキレートが生成していると荘る場合に法吸収 曲線が負になるので，1：1 ではないと考えられる。

SNT は pH 6 では注とえどコバル卜過剩の場合と一 致した吸収曲線を与えている。 
極大吸収波長は NT $<$ MNT $<$ PNT $<$ HNT,$\quad$ RT $<$ $\mathrm{DMT}<\mathrm{HCT}<\mathrm{MT}<\mathrm{HMT}$ で試薬の極大吸収波長の大 きさの順序と同じである.

極大波長の移動の大きさは NT 系は 60〜70 $\mathrm{m} \mu$ ，そ の他の試薬では 130〜150 m $\mu$ ぐらいである.

NT 系は移動が少ないので, 極大吸収波長では試薬に よる吸收が大きく測定には用いられない。

その他の試薬では RT を除いて極大波長は相互に十分 離れているので, 測定には極大波長を用いられるので, 感度の点ではすぐれている。

試薬の極大波長とキレートのそれとは，銅キレート2) の場合と同様に比例関係が成り立つ. 全体として銅キレ 一トよりはコバルトキレートは短波長側にある。また， これらのキレートは RTを除いて容易に酸化され, 緑色 のキレートに变化するので, 抽出に用いるクロロホルム の品質には注意を要する.

\section{$5 \mathrm{pH}$ の影響}

種々の $\mathrm{pH}$ の溶液のなかで生成したコバルトキレート をクロロホルムで抽出し, 吸収曲線を測定し, 定量に適 当な $\mathrm{pH}$ と波長を求めた. また, 反応時の温度について も同時に検討した。

$10^{-4} M$ コバルト溶液 $1 \mathrm{~m} l$ を種々の $\mathrm{pH}$ の緩衝溶液 $10 \mathrm{~m} l$ に加光, 試薬溶液 $1 \mathrm{~m} l$ を添加して常温をたは水 浴上で 10 分間加熱, 放冷した溶液を $10 \mathrm{ml}$ のクロロホ ルムで抽出し，クロロホルムを対照液として 550〜700 $\mathrm{m} \mu$ 間の吸収曲線を測定した。同様にコバルトを含まな い試薬のみの吸収曲線を測定した。 RT, SNT は水溶 液中で測定した.このときの吸収曲線の变化, 吸光度の 变化を検討した. 測定の結果, $\mathrm{pH}$ の変化による吸収曲 線の変化は認められず, 同一のキレートが生成している ことを示している.また，加熱の影響はニッケルの場合 と異なり，少なく、コバルトは反応がすみやかであるこ とを示している.

PNT は特に加熱の影響が大きく, 試薬の溶解度が少 ないためと考えられる. 加熱操作は煩雑なので常温に抽 出できる条件として，高い $\mathrm{pH}$ を用いることにした。

測定波長も試薬の吸収の少ない波長を選び, Table II の条件で $\mathrm{pH}$ と吸光度の関係を求め Fig. 4, 5 に示し た.

コバルトが完全に抽出される範囲の広いものは NT, MNT, HMT であり, MT, DMT, HCT は安定度が わるいため抽出範囲はせまく, HNT, PNT 溶解度が わるいために抽出範囲はせまい. SNT は $\mathrm{pH}$ 一吸光度曲 線はピークを示し, 適当な $\mathrm{pH}$ はない. $\mathrm{RT}$ 汇一定の吸
光度を与える $\mathrm{pH}$ 注広いが，いずれの場合にも水溶液中 で測定するために試薬の吸光度は $\mathrm{pH}$ とともに大きく変 化するので, 吸光光度法のための試薬としてはあまり適 当でなく，むしろ金属指示薬として適当である.

定量に適当と考えられる $\mathrm{pH}$ と波長を Table II に示 した.

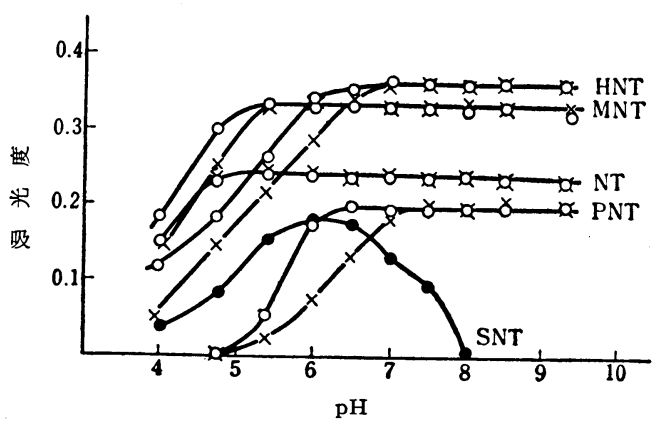

Fig. $4 \mathrm{pH}$ と财光度

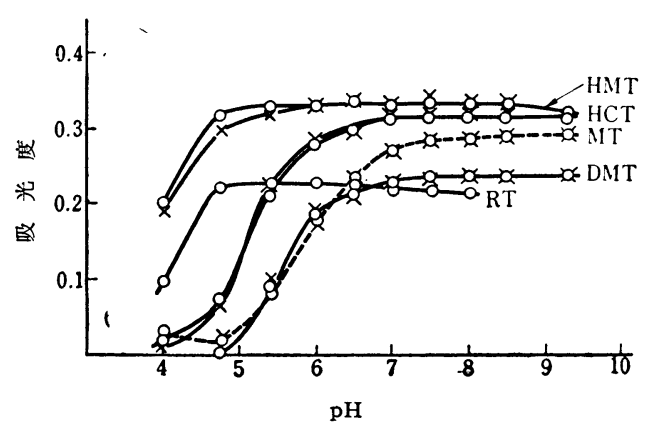

Fig. $5 \mathrm{pH}$ と财光度

6 組成の検討

\section{$6 \cdot 1$ 連綂変化法}

さきの吸収曲線の測定結果では $1: 2$ のキレートが生 成していることを示しているが, 連続変化法を用いてコ バルトキレートの組成を検討した.

$2 \times 10^{-4} M$ 試薬またはコバルト溶液を合計 $3 \mathrm{ml}$ にな るように混合して pH 8.0 に調節した緩衝溶液 $10 \mathrm{ml}$ に 加え, 約 10 分間放置したのち $10 \mathrm{~m} l$ のクロロホルムで 抽出し，550〜 700 $\mathrm{m} \mu$ 間の吸収曲線をクロロホルムを対 照液として測定した.

$\mathrm{RT}, \mathrm{SNT}$ 蝺衝溶液 $5 \mathrm{~m} l$ に上記試薬, コバルト溶 液を合計 $3 \mathrm{~m} l$ になるように添加，全容を $10 \mathrm{~m} l$ として， 水を対照液として測定した。この結果, SNT 老除いて は吸収曲線の型から同一のキレートが生成していること 
がわかった。

吸収曲線を一定の波長で切って組成を検討した結果は Fig. 6 に示すように, いずれも $1: 2$ のキレートが生 成していることを示している。

$\mathrm{SNT}$ では pH 5 および 6 ではキレートの解離が大き く, ピークの位置から 1:1 と 1:2 のキレートが混合 して生成していることがわかり， pH 7 以上ではほとえ ど 1:2のキレートであることを示している.

この傾向は二ッケルの場合にも認められ33, 水溶液中 では SNT は比較的安定に $1: 1$ のキレートを生成する ことがわかった。

\section{$6 \cdot 2$ 等吸収点}

吸収曲線の測定および連続変化法の結果, 試薬とコバ ルトの量に関係なく, $1: 2$ のキレートを生成している ことがわかった，従って等吸収点を示すはずである.

$2 \times 10^{-4} M$ 試薬 $2 \mathrm{ml}$ と $2 \times 10^{-4} M$ コバルト溶液 $0 \sim$ $0.8 \mathrm{ml}$ を緩衝溶液 $10 \mathrm{ml}(\mathrm{RT}, \mathrm{SNT}$ は $5 \mathrm{ml})$ に添加 し, $10 \mathrm{ml}$ のクロロホルムで抽出し (RT, SNT は水で 正確に $10 \mathrm{ml}$ にうすめる), クロロホルム (RT, SNT は水）を対照液として 550～700 $\mathrm{m} \mu$ 間の吸収スペクト ルを測定し，等吸収点の有無を検討した。この結果を Table II に示した.

いぶれも等吸収点を有し， $1: 2$ のキレートが生成し
ていることを示している. SNT では正確でないが 518 $\mathrm{m} \mu$ に集まる.これはこの $\mathrm{pH}$ では 1:1 のキレートも 生成しているためと考えられる.

Table II コバルト定量条件, 等吸収点

\begin{tabular}{lccc}
\hline \hline 試 薬 & 測定 $\mathrm{pH}$ & 測定波長 $(\mathrm{m} \boldsymbol{\mu})$ & 等吸収点 $(\mathrm{m} \mu)$ \\
\hline NT & 8.0 & 600 & 508 \\
MNT & 8.0 & 600 & 516 \\
HNT & 8.0 & 600 & 527 \\
PNT & 8.0 & 600 & 535 \\
MT & 8.0 & 612 & 515 \\
HMT & 8.0 & 624 & 529 \\
HCT & 8.0 & 601 & 505 \\
DMT & 8.0 & 591 & 494 \\
RT & 6.0 & 580 & 470 \\
SNT & 6.0 & 600 & 518 \\
\hline
\end{tabular}

7 試薬の濃度, モル吸光係数

完全にキレートを生成させるためにどれだけの試薬が 必要であるかを検討し, あわせてキレートのモル吸光係 数および測定波長における 試薬自身の吸光度を測定し た. 緩衝溶液 $10 \mathrm{ml}$ に試薬溶液 $0.5 \sim 4 \mathrm{ml}$ とコバルト溶 液 $\left(10^{-4} M\right) 1 \mathrm{ml}$ とを添加し, クロロホルムで抽出を繰 返して抽出液を $10 \mathrm{ml}$ のフラスコに移し, クロロホルム で正確に $10 \mathrm{ml}$ とし, それぞれの波長における吸光度を 測定し, 同様にして, コバルトのみ含まない溶液につい

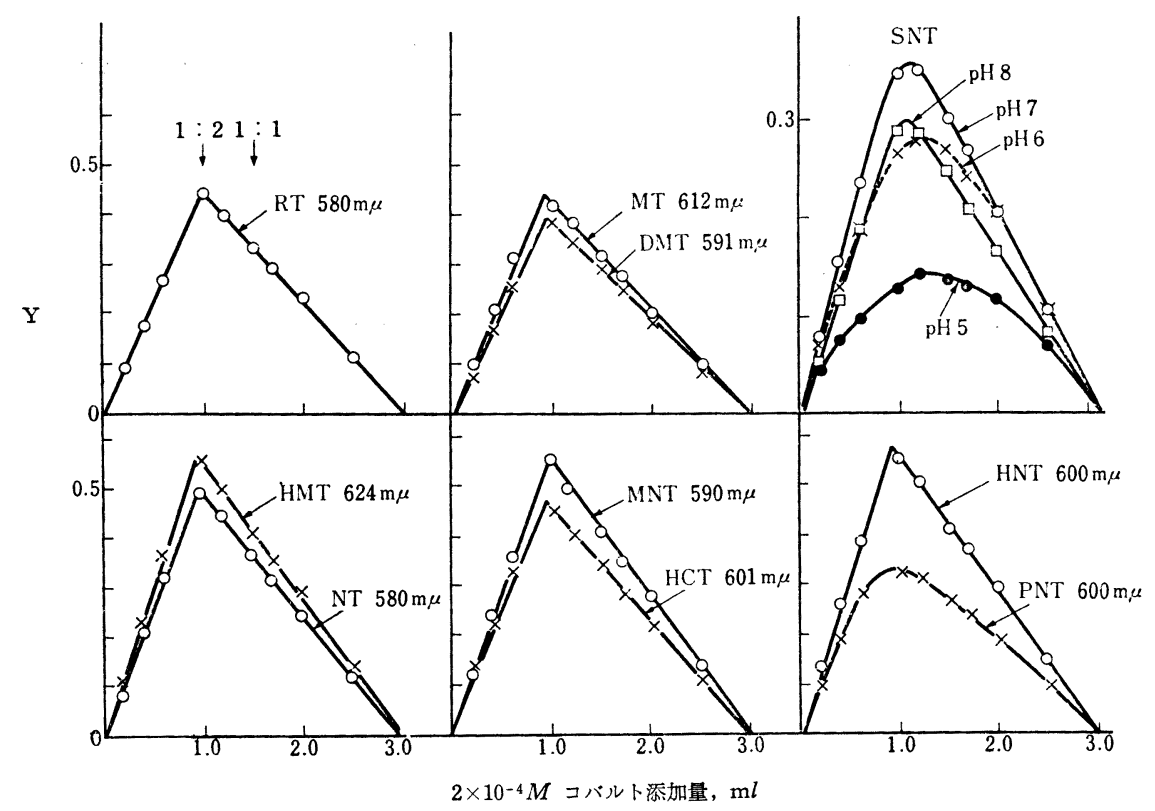

Fig. 6 連 続 変 化 法

緩衙溶液 pH 8.0 (ただし RT 6.0) 
Table III 試薬濃度, モル财光係数

\begin{tabular}{|c|c|c|c|c|c|c|c|c|c|c|}
\hline \multirow{2}{*}{ 試 薬 $(\mathrm{m} l)$} & \multicolumn{5}{|c|}{ 财 } & \multicolumn{2}{|c|}{ 度 } & \multirow[b]{2}{*}{$\begin{array}{l}\text { DMT } \\
591 \mathrm{~m}^{\mu}\end{array}$} & \multirow[b]{2}{*}{$\begin{array}{l}\text { SNT } \\
600 \mathrm{~m} \mu\end{array}$} & \multirow[b]{2}{*}{$\underset{580 \mathrm{~m} \mu}{\mathrm{RT}}$} \\
\hline & $\begin{array}{c}\mathrm{NT} \\
600 \mathrm{~m} \boldsymbol{\mu}\end{array}$ & $\begin{array}{c}\text { MNT } \\
600 \mathrm{~m}_{\boldsymbol{\mu}}\end{array}$ & $\begin{array}{l}\text { HNT } \\
600 \mathrm{~m} \mu\end{array}$ & $\begin{array}{l}\text { PNT } \\
600 \mathrm{~m} \mu\end{array}$ & $\begin{array}{c}\mathrm{MT} \\
612 \mathrm{~m} \mu\end{array}$ & $\begin{array}{l}\mathrm{HMT} \\
624 \mathrm{~m} \mu\end{array}$ & $\begin{array}{l}\mathrm{HCT} \\
601 \mathrm{~m} \mu\end{array}$ & & & \\
\hline 0.5 & 0.231 & 0.323 & 0.277 & $0.144 \dagger$ & $0.275 \dagger$ & 0.332 & 0.295 & $0.210 \dagger$ & 0.137 & 0.225 \\
\hline 1.0 & 0.230 & 0.321 & 0.332 & $0.218 \dagger$ & 0.284 & 0.330 & 0.294 & 0.236 & 0.166 & 0.224 \\
\hline 2.0 & 0.231 & 0.320 & 0.337 & 0.234 & 0.287 & 0.330 & 0.294 & 0.237 & 0.188 & 0.221 \\
\hline 3.0 & 0.234 & 0.323 & 0.329 & 0.235 & 0.285 & 0.337 & 0.291 & 0.235 & 0.191 & 0.218 \\
\hline 4.0 & 0.236 & 0.323 & 0.326 & 0.235 & 0.286 & 0.334 & 0.287 & 0.236 & 0.195 & 0.215 \\
\hline モ ル 吸 光 係 数 $\left(\times 10^{-4}\right)$ & 2.34 & 3.22 & 3.31 & 2.35 & 2.86 & 3.33 & 2.93 & 2.36 & - & 2.21 \\
\hline 極大吸収波長におけるモル吸光原数 $\left(\times 10^{-4}\right)$ & 3.87 & 4.56 & 3.50 & 2.80 & 2.86 & 3.33 & 2.93 & 2.36 & - & 5.11 \\
\hline の 吸 & 0.002 & 0.010 & 0.032 & 0.034 & 0.008 & 0.002 & 0.001 & $<0.001$ & 0.039 & 0.006 \\
\hline
\end{tabular}

て吸光度を測定し, 試薬および不純物による吸光度を求 めて差引いた。

$\mathrm{RT}, \mathrm{SNT}$ 以緩衝溶液のみ $5 \mathrm{~m} l$ とし, $10 \mathrm{~m} l$ の水溶 液として測定した。これらの結果により，モル吸光係数 を測定した。また，同時に試薬溶液 $1 \mathrm{~m} l$ に対する測定 波長における試薬自身の吸光度を計算した。

NT 系および RT では極大吸収で試薬の吸収が大き いためそれより長波長側の吸収を用いている.従って, 極大吸収波長におけるモル吸光係数注求められないが, 吸収曲線より間接的に算出できるのでこの結果をTable III に示した.

試薬の量は PNT, SNT を除いては $10^{-4} M$ コバル 卜溶液 $1 \mathrm{~m} l$ に対し 10 倍の試薬で十分であるが, PNT は $2 \mathrm{~m} l$ 必要である. SNT は $4 \mathrm{~m} l$ を用いても一定の 吸收を示さない。あまり試薬裖度を高くすることは空実 験值の増加をま㱛くので, $2 \mathrm{~m} l$ を用いることにした。

極大吸收波長におけるモル吸光係数怯 $2 \sim 5 \times 10^{4}$ 程度 で高い感度をもっている. モル吸光係数の大きさの序列 は試薬のモル吸光係数のそれとほぼ一致する.

定量測定波長に尔けるモル吸光係数はHMT, MNT, HNT が大きく, HCT, MT は比較的小さい。

試薬自身の吸収は PNT, HNT, SNTでは定量に選 んだ波長においても多少あるが，この程度では定量には さしつかえがないと考光られる。

$$
8 \text { 結 果 }
$$

以上実験の結果, コバルト定量に最も適している試薬 を検討する. 抽出性の点で汢 NT 系や HMTがすぐれ ており，MT，DMT は他に比してわるいようである。 従って, 抽出して吸光光度定量するには NT 系の試薬 や HMT がよく, 金属指示薬としては MT, DMT, SNT, RT がすぐれており, 特に MT は变色の明瞭な 点では推奨できる.

キレート吸収帯の移動の大きさは RT, NT 系では小
さいため吸収帯の分離が十分でなく, 極大吸収波長にお ける試薬の吸収は大きいので, 感度をぎせいにしてより 長波長側の吸収を用いなければならない。

この点その他の試薬は波長の移動が大きく, 吸収帯は 十分分離している.PNT, HNTなどでは水汶対する溶 解度が小さいため低い $\mathrm{pH}$ ではコバルトの反応には時間 を要するが, NT やその他の試薬ではすみやかに反応す る.

NT 系以外の試薬ではキレートの安定度が小さいため 抽出範囲がせをい。

これらを総合すると，HMT と NT が抽出試薬とし ては最もすぐれており，金属指示薬としてはSNT， MT, DMT, RT などがすすめられると考える.

(昭和 34 年 9 月, 本会第 8 年会に一部発表)

$$
\text { 交献 }
$$

1）柳原 正, 俣野宣久, 川瀬 晃: 本誌, 7,496 , 500 (1958); 8, 10,14 (1959); 9, 344 (1960). 川瀬 晃：同上, 11, 621 (1962).

中川元吉, 和田弘子：日化, 83, 1185 (1962).

2) 川瀬 晃 : 本誌, 11, 628 (1962).

3) 川瀬 晃: 同上, 12, 810 (1963).

$$
\text { 约 }
$$

Determination of cobalt(II) with o-(2-thiazolylazo) phenol derivatives. Akira KawASE (National Research Institute for Metals, Meguro-ku, Tokyo)

The reaction of $o$-(2-thiazolylazo) phenol compounds ${ }^{1}$ with cobalt gives products with redpurple or blue coloration and the chelates can be extracted with chloroform. Since they have molecular extinction coefficients of $2 \sim 5 \times 10^{4}$ at their maximum absorption wavelengths of $550 \sim$ $600 \mathrm{~m} \mu$ (Table I and Fig. 1 and 2), the determination of a small amount of cobalt by them may be possible.

The combining ratio of the metal to the reagent was found to be $1: 2$ (Fig. 6).

The conditions for determination of cobalt by these reagents have been investigated. NT and HMT were suitable as reagents for extraction and SNT, MT, DMT and RT were excellent as metal indicators.

(Received May 6, 1963) 